\title{
The role of immunogenic cell death in gastrointestinal cancer immunotherapy (Review)
}

\author{
WORAWAT SONGJANG ${ }^{1,2}$, CHATCHAI NENSAT $^{3}$, SUTATIP PONGCHAROEN $^{4}$ and ARUNYA JIRAVIRIYAKUL ${ }^{1,2}$ \\ ${ }^{1}$ Department of Medical Technology; ${ }^{2}$ Integrative Biomedical Research Unit (IBRU); ${ }^{3}$ Biomedical Sciences, \\ Faculty of Allied Health Sciences; ${ }^{4}$ Division of Immunology, Department of Medicine, \\ Faculty of Medicine, Naresuan University, Phitsanulok 65000, Thailand
}

Received April 23, 2021; Accepted July 30, 2021

DOI: $10.3892 /$ br.2021.1462

\begin{abstract}
Modern cancer immunotherapy techniques are aimed at enhancing the responses of the patients' immune systems to fight against the cancer. The main promising strategies include active vaccination of tumor antigens, passive vaccination with antibodies specific to cancer antigens, adoptive transfer of cancer-specific T cells and manipulation of the patient's immune response by inhibiting immune checkpoints. The application of immunogenic cell death (ICD) inducers has been proven to enhance the immunity of patients undergoing various types of immunotherapy. The dying, stressed or injured cells release or present molecules on the cell surface, which function as either adjuvants or danger signals for detection by the innate immune system. These molecules are now termed 'damage-associated molecular patterns'. The term 'ICD' indicates a type of cell death that triggers an immune response against dead-cell antigens, particularly those derived from cancer cells, and it was initially proposed with regards to the effects of anticancer chemotherapy with conventional
\end{abstract}

Correspondence to: Dr Arunya Jiraviriyakul, Department of Medical Technology, Faculty of Allied Health Sciences, Naresuan University, 99 Moo 9 Phitsanulok-Nakhonsawan Road, Tha Pho Subdistrict, Mueang, Phitsanulok 65000, Thailand

E-mail: arunyaj@nu.ac.th

Abbreviations: PC, pancreatic cancer; HCC, hepatocellular carcinoma; CRC, colorectal cancer; GC, gastric cancer; ICD, immunogenic cell death; HMGB1, high mobility group box 1; CRT, calreticulin; MDSC, myeloid-derived suppressor cell; DC, dendritic cell; NK cells, natural killer cells; Treg, regulatory $\mathrm{T}$ cell; CTL, cytotoxic T lymphocyte; TLR, Toll-like receptor; PD-1, programmed death 1; PD-L1, programmed death ligand 1; CY, cyclophosphamide; FOLFOX, oxaliplatin, 5-FU and leucovorin; FOLFOXIRI, FOLFOX and irinotecan; 5-FU, 5-fluorouracil; HSP, heat shock protein; CBP, calmodulin-binding peptide; NIR-PIT, near-infrared photoimmunotherapy; CTLA-4, CTL-associated protein 4; eIF2a, eukaryotic translation initiation factor $2 \mathrm{~A}$

Key words: immunogenic cell death, gastrointestinal cancer, immunotherapy, immune response cytotoxic drugs. The aim of the present study was to review and discuss the role and mechanisms of ICD as a promising combined immunotherapy for gastrointestinal tumors.

\section{Contents \\ 1. Introduction \\ 2. GI cancers \\ 3. Immunotherapy in GI cancers \\ 4. Vaccine therapy in GI cancers \\ 5. Cancer vaccination is the target of ICD \\ 6. Checkpoint inhibitor therapies in GI cancers \\ 7. Induction of ICD sensitizes blockade inhibitor therapies \\ 8. Adoptive therapies in GI cancer \\ 9. Implications of ICD and adoptive cell transfer \\ 10. Conclusions}

\section{Introduction}

Modern cancer immunotherapy has been proposed to involve four primary promising strategies: i) Active vaccination of tumor antigens, ii) passive vaccination with antibodies specific to cancer antigens, iii) adoptive transfer of cancer-specific $\mathrm{T}$ cells, and iv) manipulation of the patient's immune response by inhibiting immune checkpoints. Additional emerging strategies include other antigen-non-specific interventions, including the applications of oncolytic or immune-enhancing viruses, innate immunity stimulators and immunogenic cell death (ICD) inducers (1). The focus of the present review was to describe the treatments that employ ICD to enhance the immunity of patients with gastrointestinal (GI) cancers.

The daily death of billions of ordinary cells from the human body goes essentially unrecognized by the immune system. This is crucial since the conservation of the entire bodies homeostasis includes the continuous turnover of various cell compartments. As such, the initiation of an immune response against dead-cell antigens would have detrimental outcomes. Conversely, the death of a few cells infected by a microorganism can trigger a potent antigen-specific immune reaction, which is associated with the clearance of the invading pathogen from the body and also enables the establishment of long-term 
immunological memory (2). The first proposal of the 'danger theory' in 1994 by Matzinger (3) was that the immune system can distinguish between dangerous and innocuous endogenous signaling. In her famous essay, Matzinger suggested that 'unprogrammed cell death' could give rise to the unusual release of internal molecules from the cytoplasm, nucleus or membrane to activate dendritic cells (DCs). The dying, stressed or injured cells release or present molecules on the cell surface, which can function as either adjuvants or danger signals for detection by the innate immune system. These molecules are now termed 'damage-associated molecular patterns' (DAMPs) (4). The term 'ICD' was introduced to indicate a type of cell death that triggers an immune response against dead-cell antigens, particularly those derived from cancer cells, including DAMPs. This model was initially proposed with regard to anticancer chemotherapy, in view of clinical proof demonstrating that tumor-specific immune responses reflect the efficacy of anticancer treatments using conventional cytotoxic drugs (5).

Currently, various routinely employed anticancer agents include doxorubicin, epirubicin, idarubicin, mitoxantrone, bleomycin, bortezomib, cyclophosphamide (CY) and oxaliplatin. The list also includes certain anticancer agents that are currently under preclinical or clinical development, such as some microtubular inhibitors of the epothilone family. Certain drugs, including digoxin, digitoxin and zoledronic acid, act to convert otherwise non-immunogenic events of cell death into bona fide ICD inducers, and may thus be used as adjuvants in combinatorial immunotherapy regimens (6). The known clinically applied or experimental anticancer agents that induce ICD act via one or several of the following mechanisms: Inducing apoptosis, causing a severe focused stress of the endoplasmic reticulum, overcoming loss-of-function mutations that hide danger signals during tumorigenesis and downregulating the cancer-based induction of pro-inflammatory transcription factors (4). In addition, one important consideration is the complex interactions with DAMPs and their receptors, known as the pattern recognition receptors. Attempts have been made to identify and detect multiple DAMPs in order to facilitate the development of next-generation anticancer regimens, which, in addition to killing cancer cells, can simultaneously convert them into a cancer-specific therapeutic vaccine (7).

\section{GI cancers}

GI cancers are amongst the malignancies most frequently diagnosed in European patients. These include gastric cancer (GC), colorectal cancer (CRC), as well as cancers affecting the liver, particularly hepatocellular carcinoma (HCC), the biliary tract, such as cholangiocarcinoma (CCA), and the pancreas (pancreatic cancer; PC). The frequency with which these conditions are diagnosed presents a significant challenge for public health systems in Europe and worldwide (8).

Different cancers of the GI tract. Most commonly reported in patients in Asia, GC is notable for its particularly poor survival rates. The condition is associated with certain bacterial infections, such as Helicobacter pylori (H. pylori) infection, and the effects of other pathogens, including Epstein-Barr virus (9).
The annual number of new CRC diagnoses falls in the range of 1-2 million cases, placing $\mathrm{CRC}$ third in terms of the most frequently occurring cancers, and fourth amongst the most common causes of cancer-related mortality. The main $\mathrm{CRC}$ risk factors include age and history of chronic disease, as well as various aspects of patient lifestyles. There are three different pathogenic mechanisms that can lead to the onset of CRC: Microsatellite instability, chromosomal instability and a $\mathrm{CpG}$ island methylator phenotype $(10,11)$.

The most common type of liver cancer is $\mathrm{HCC}$, which originates from hepatocytes and accounts for $\sim 4$ in 5 liver cancer diagnoses, with an increased prevalence in China and Eastern Africa (12). The onset of HCC is often a consequence of the interaction between genetic characteristics and environmental factors. In particular, patients diagnosed with liver cirrhosis, or infection with the hepatitis B virus (HBV) or the hepatitis $\mathrm{C}$ virus (HCV), are more likely to develop $\mathrm{HCC}$, while other risk factors include alcohol abuse, the ingestion of aflatoxin B1 or non-alcoholic steatohepatitis $(13,14)$.

CCA is the second most frequently occurring primary hepatic cancer after HCC. CCA has been most commonly reported across Asia, although in recent years it has become increasingly more widespread in North America and Europe $(15,16)$. CCA originates in the biliary tract and is subdivided by location into three different subtypes, namely perihilar, intrahepatic and distal CCA. Several risk factors, both common and rare, have been associated with CCA, including hepatobiliary parasites, Caroli disease, HBV and HCV infection, and exposure to toxins (17-19).

$\mathrm{PC}$ is the 14th most prevalent type of cancer and the seventh largest cause of annual cancer-associated deaths globally. PC risk factors include obesity, alcohol consumption and smoking, as well as $H$. pylori infection (20).

Latest approaches to GI cancer treatment. Several potential treatments are currently being developed for GI cancers. A number of these are targeted approaches that make use of biological properties to achieve their objectives, and can be employed alone or as components of combination or adjuvant treatments. The most widely applied treatments at present include surgery, as a means of resecting solid tumors; radiation therapy, as a means of managing localized solid tumors; chemotherapy, which involves the use of cytotoxic agents to eliminate cancerous cells; and hormonal therapy, which serves as a systematic approach with the aim of targeting all cancerous cells found in the body (21-23).

\section{Immunotherapy in GI cancers}

Patients diagnosed with GI cancers are typically subjected to a combination of treatments, including surgery, chemotherapy and/or radiation therapy; however, the survival rates remain poor, particularly when the cancer has reached an advanced stage, or in the case of metastatic disease $(24,25)$. For this reason, it is imperative to develop more effective, novel techniques to address the problem, and immunotherapy appears to hold promise for this purpose. To date, a number of cytokines, including IFN- $\gamma$ or IL-2, have been used to limit the activity of certain types of cancer, such as renal cell carcinoma and melanoma, and a moderate level of inhibitory activity has been reported (26). However, 
the development of cancer vaccines has been less successful, with none generating statistically significant responses in test patients (23).

The progress in immunotherapy shows great potential in the context of GI cancers, whereas further therapies involving the administration of immunostimulatory monoclonal antibodies to treat GI malignancies are currently in their developmental phase. Immune checkpoint blockade is the primary type of immunotherapy currently used in GI cancer treatment. It can be anticipated that the vaccination approach will be streamlined with the lessons learned from initial successes, and the most suitable tumor-associated antigens will be identified for targeting. Adoptive cell therapies are now at an advanced stage of development and appear to hold significant promise for GI cancers. An improved understanding of the prevalent suppressive factors in patients with GI cancers may enable the development of superior strategies to limit immune suppression and promote endogenous immunity in patients. It is likely that deeper knowledge of the tumor microenvironment and the field of immunology will lead to the successful development of more efficacious treatments in the near future.

\section{Vaccine therapy in GI cancers}

Various cancer vaccines have been developed to date by using different technologies, including recombinant microorganisms, recombinant antigen cocktails, oncolytic viruses, DNA and gene therapy-based treatments, and anti-idiotypic antibodies. In addition, personalized vaccines have also been devised, including those based on adoptive cell transfer, or autologous cells and antigens. These may be more complex, and require specialized manufacturing approaches and expertise (27). However, although several trials have been conducted, approval has only been granted for one vaccine, which acts against metastatic castration-resistant prostate cancer. This vaccine is Dendreon's Provenge ${ }^{\circledR}$ (Sipuleucel-T), which was approved by the Food and Drug Administration in $2010(28,29)$. Furthermore, two additional cancer vaccines, Vitespen ${ }^{\circledR}(30)$ and Melacine ${ }^{\circledR}(31)$, were approved in Russia and Canada, but not in the United States. These cancer vaccines rely upon the activation and strengthening of antitumor responses that target cancer. The dendritic cell-based cancer vaccine presents antigens and serves a critical role in formulating the immune response. They can also activate B cells, natural killer (NK) cells, as well as naïve and memory T cells, through the presentation of tumor antigens associated with major histocompatibility complex (MHC) molecules. When patients with cancer have higher numbers of DCs penetrating the tumors, this is a sign of reduced lymph node metastases and improved chances of survival (32). A number of approaches have been employed to create vaccines by loading DCs with tumor antigens. These include the use of synthetic peptides pulsed on DCs (33), DCs engineered with plasmid DNA (34), RNA (35) or viruses (36), tumor cell lysates combined with immature DCs (37) and, finally, DCs combined with whole tumor cells through polyethylene glycol or electroporation (38). The technique that uses DCs pulsed with MHC-restricted peptides, which are obtained from antigens known to be associated with tumors, is the most common type of vaccine approach (39-41). However, it can be challenging to use DCs for clinical purposes, as these cells have a relatively short life span (42). To date, vaccines have shown little effectiveness in preventing GI cancers. The vaccines developed thus far have targeted melanoma-associated antigen (MAGE)-A3 (43), HER2 p369 peptide (44), gastrin-17 diphtheria toxoid (45), URLC10 or VEGFR1 epitopes (46) and heat shock protein (HSP) gp96 (47) in patients with GI cancers. Furthermore, chemotherapy has been tested alongside adjuvant Bacillus Calmette-Guérin (48). In cases of PC, a number of specific antigens serve as targets, including carcinoembryonic antigen (CEA), EGFR, Wilms' tumor 1 and VEGF, whereas GVAX ${ }^{\circledR}$ is a whole-cell vaccine that has been tested in trials in the metastatic, neoadjuvant and adjuvant settings. Positive outcomes have been reported in the metastatic setting when combined with ipilimumab, with a reported survival rate of $27 \%$ after 1 year (49).

In the case of HCC, vaccines have shown no efficacy thus far. However, immune responses have been reported in phase I trials involving peptide vaccines (50), DC vaccines and tumor-associated antigens targeting oncolytic viruses, such as AFP (51), GPC-3 (52) and human telomerase reverse transcriptase (53). DC-based vaccines have been included in trials on CCA, whereas a phase II study was conducted in the adjuvant setting in order to target mucin 1 (MUC1) in the biliary tract and in PC via DC vaccination, and the tolerability was reported to be good, although it was not possible to draw definitive conclusions regarding the immune response (54). Further phase II clinical trials involving CRC-specific peptide vaccines were performed with patients diagnosed with HLA-A*2402-positive stage III CRC, with the findings suggesting that an immune response would be generated by the vaccine, leading to higher survival rates (55). For patients with PC, 13-mer mutant ras peptide vaccines were not only shown to be safe, but to also generate the appropriate immune response (56). Additionally, the p53 synthetic long peptide vaccine has been shown to be safe for patients with metastatic CRC in whom specific T-cell responses were induced (57). However, several issues must be addressed if a novel cancer vaccine is to be approved, including commercial, clinical, manufacturing, operational and regulatory concerns. Risk evaluation must also be conducted to make full use of the expertise available. Moreover, a number of clinical studies revealed that some patients may not benefit from the cancer vaccine treatment (primary resistance), and some responders may relapse after a period of response (acquired resistance). For example, PC is associated with the presence of a highly immunosuppressive microenvironment, which is characterized by a dense desmoplastic stroma that impedes blood flow to the area, inhibits drug delivery and suppresses antitumor immune response (58). In CRC and GC, it has been shown that only patients with the subset of mismatch-repair-deficient or microsatellite instability-high tumors are likely to respond to immunotherapy $(59,60)$. Once these issues have been addressed, ICD may prove to be the answer for vaccine development.

\section{Cancer vaccination is the target of ICD}

DC maturation is a crucial step for immune activation. Once in the lymph nodes, DCs activate T cells via three canonical signals: Binding of T-cell receptors, co-stimulatory receptor 
engagement, and the provision of cytokines and chemokines to facilitate T-cell polarization and differentiation. The ICD complementarily activates DCs. High mobility group box 1 (HMGB1) and HSP activate pro-inflammatory DCs through the Toll-like receptor (TLR)2/4-MyD88-NF- $\kappa$ B signaling pathway (61). Moreover, dying cancer cells also express calreticulin (CRT) on their plasma membrane, which signals to facilitate engulfment by DCs. The exposed CRT on the cell membrane can bind to CD91, the low-density lipoprotein-receptor-related protein 1 , which promotes the engulfment of cellular compartments and debris by a mechanism that depends on the Rac family small GTPase 1 (61). Hence, the original concept for using the combination treatment of ICD stimulation and DC-based anticancer vaccines originated from significant evidence that cancer treatments, such as chemotherapy, radiation, phototherapy, phytotherapy and immunotherapy, could elicit danger signals from dying cancer cells. Notably, chemoradiotherapy is known to elevate serum HMGB1 in patients with esophageal squamous cell carcinoma, and the levels of HMGB1 were found to be positively correlated with patient survival (62). Moreover, oxaliplatin and mitoxantrone induced cancer cell death accompanied by an exposure of CRT and a release of HMGB1, HSP70 and ATP, thereby strongly inducing in vitro immune responses of DCs $(63,64)$. Interestingly, it has been demonstrated that pretreatment with the oxaliplatin nanoparticle followed by a rechallenge by tumor inoculation in PC-bearing mice can enhance therapeutic efficacy by increasing the numbers of tumor-infiltrating activated cytotoxic T cells (64). In addition to the use of chemotherapy, botanical cancer therapy has also been introduced. Treatment with Hemidesmus indicus was shown to induce CRC cell apoptosis characterized by surface expression of CRT, increased HSP70 expression, and a release of ATP and HMGB1. This immunogenic agent is promising when combined with a DC-based anticancer vaccine (Table I) (65). Recently, our group demonstrated that a potent bioactive compound, honokiol, can induce CCA cell apoptosis, which is associated with the release of HMGB1 and HSP90. Incubation of DCs with CCA cells that were pretreated with honokiol induced DC maturation, and thus enhanced the priming of cytotoxic T cells to kill cancer cells (37). Therefore, the priming of DCs with immunogenic agents may maximize antitumor responses though DC stimulation.

Radiation as a cancer treatment also induces ICD, which may pave the way for anticancer vaccines in such patients. For example, in large orthotopic HCC, synergistic antitumor effects may be obtained when radiation is combined with the administration of IL-12. This has been shown to be associated with the activation of tumor-infiltrating $\mathrm{DCs}, \mathrm{CD}^{+} \mathrm{T}$ cells and NK cells, as well as the suppression of tumor-infiltrating myeloid-derived suppressor cells (MDSCs) (66). Similar to radiation, phototherapy has been suggested to be a new platform for enhancing the immunogenicity of cancer. Photodynamic and photothermal therapies proficiently promote immunotherapy via the induction of ICD. In addition, phototherapy combined with oxygenation boosters can promote CRC cell apoptosis and induce ICD, thus facilitating DC maturation and inhibiting tumor growth and recurrence in animal models (67). Plasma-treated PBS, which is physical cold atmospheric plasma consisting of reactive oxygen and nitrogen species, has demonstrated cytotoxic activity against PC cells with immunogenic features. This increases the potential of phagocytosing DCs and DC maturation, which may hold promise for combinations with DC cancer vaccines (68).

Several clinical studies have corroborated the concept that ICD-inducing pretreatment may act as an immunomodulator (Table I). There are $~ 50$ trials currently investigating the benefit of ICD in vaccines against cancer, mostly PC and CRC. A phase I/II trial study, in which 22 patients with $\mathrm{HCC}$ have been enrolled, is investigating treatment interventions comprising pre-infusion of $\mathrm{CY}$ and vaccination using a multi-peptide-based HCC vaccine (IMA970A) plus CV8102 adjuvant ( RNAdjuvant $^{\circledR}$ ). This trial is investigating whether IMA970A and CV8102 are safe and whether they can trigger an immune response against the tumor under pre-conditioning by induction of ICD (NCT03203005). Moreover, mFOLFOX6, which is a formulation of 5-fluorouracil (5-FU), leucovorin and oxaliplatin, has been used in combination with nivolumab and vaccination with a CV301 peptide vaccine in patients with advanced CRC (NCT03547999). Another clinical trial including patients with $\mathrm{PC}$ used $\mathrm{CY}$ followed by vaccination with a GVAX peptide cancer vaccine. However, pretreatment with CY did not improve overall survival or disease-free survival when compared with the uncombined intervention (NCT00727441). Collectively, the majority of preclinical and clinical data have demonstrated that combining the immunogenic potential of ICD with cancer vaccination is a promising approach that could achieve future translational success.

\section{Checkpoint inhibitor therapies in GI cancers}

The field of immuno-oncology has witnessed significant advances with regard to immune checkpoint inhibitors (ICIs). Immune checkpoints are the mechanisms through which T-cell immune responses are regulated (69). Tumor cells are considered to be able to avoid host immune clearance when T-cell immune responses are downregulated. If immune checkpoints can be targeted, the endogenous response of the immune system to tumors may be used as a means of addressing the risk of disease. A number of antibodies have been shown to be effective against immune checkpoints, and more are under examination (69). These antibodies most commonly serve to target cytotoxic T lymphocyte-associated protein 4 (CTLA-4), programmed death-1 (PD-1) and programmed death-ligand 1 (PD-L1). CTLA-4 acts as a receptor capable of inhibiting the activation of T cells (70). Accordingly, when CTLA-4 is blocked, the $\mathrm{T}$ cells will proliferate and become activated. PD-1 is expressed on T cells and other immune cells, and PD-L1 serves as one of its ligands. PD-1 and PD-L1 binding creates an inhibitory signal affecting T cells; by contrast, if the binding is inhibited, the T cells will become activated, leading to a heightened response from cold tumor (non-inflammatory T-cell) to hot tumor (inflammatory T-cell) immune response (71-73). Another targeted checkpoint receptor protein is the lymphocyte activation gene-3, which may control the activity of T cells through its binding with MHC class II-molecules (74). However, earlier studies examining such checkpoint inhibitors in CRC were not very successful, phase II trials involving the CTLA-4 inhibitor, tremelimumab, in patients diagnosed with metastatic CRC have shown no significant levels of efficacy $(75,76)$. 


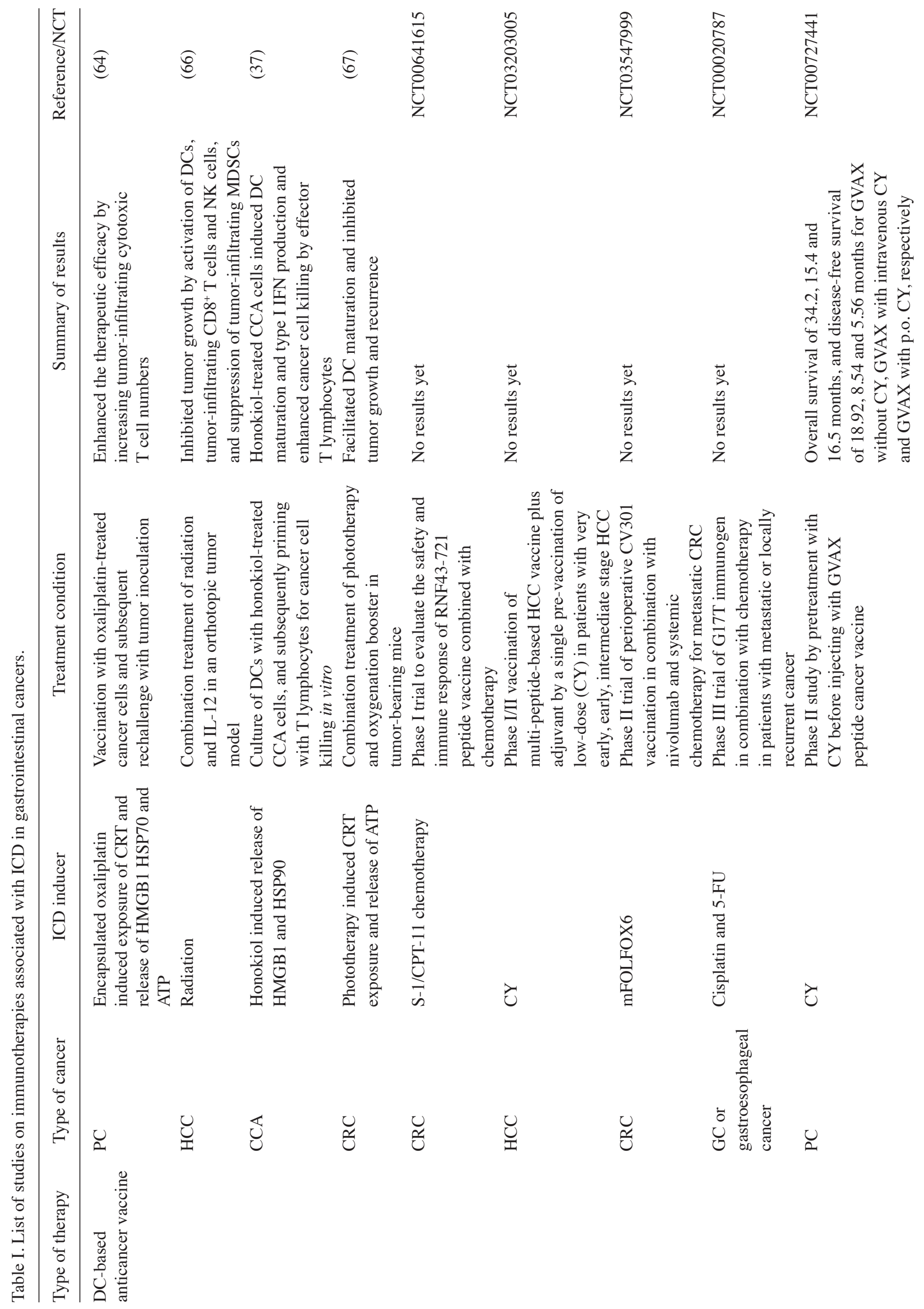




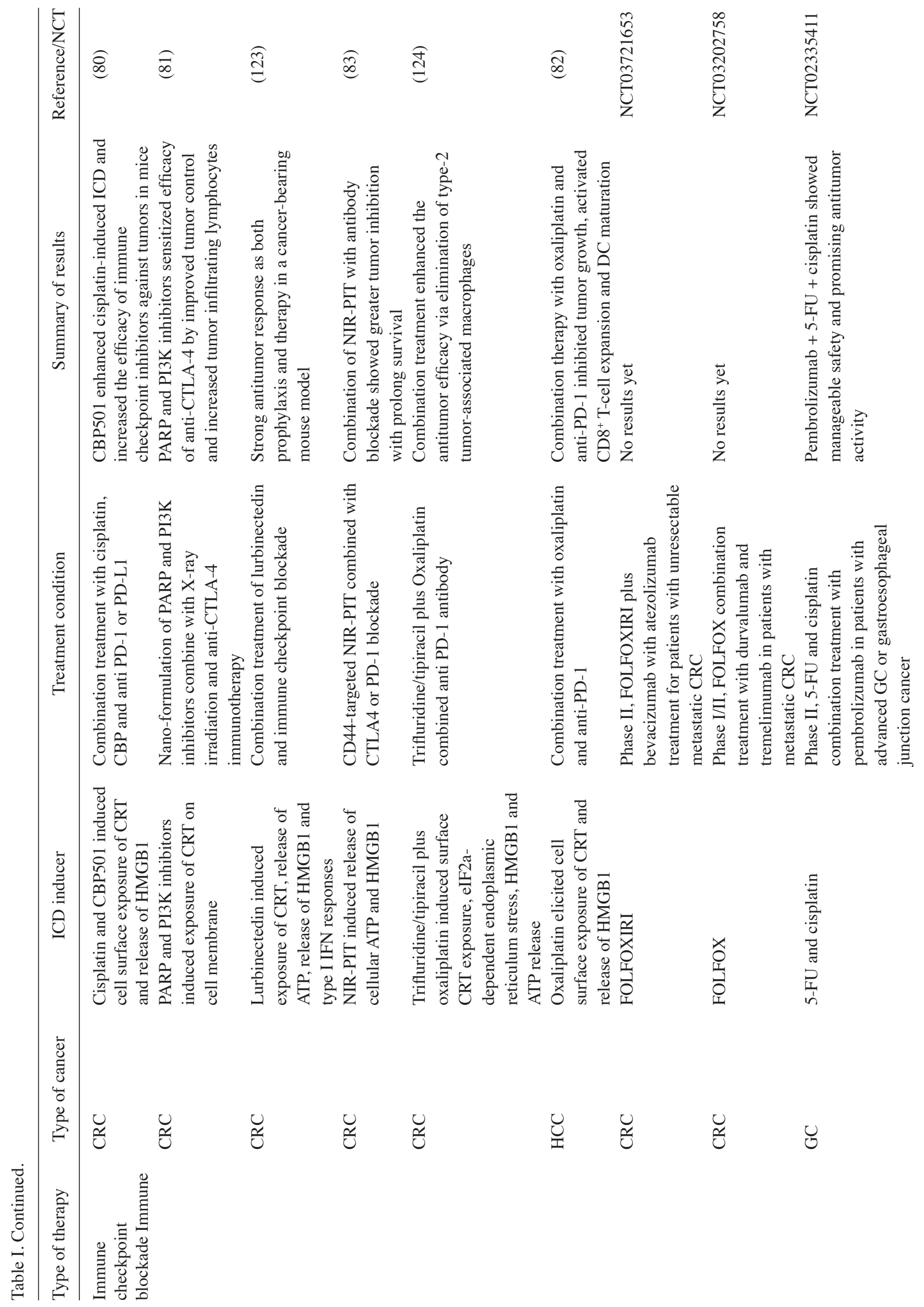


As a consequence of tumor heterogeneity, along with the complexity of immunosuppression, treatment of GC, as has been the case with CRC, has shown little success in the area of immunotherapy, for reasons possibly related to mechanisms that are incompletely understood. Previous findings have revealed that a certain level of checkpoint inhibition can be achieved, often in correlation with enhanced classification and characterization of GC and an improved understanding of its histopathology (48). PC presents the greatest challenge amongst all types of GI cancer in the context of immunotherapy, most likely as a result of inadequate immunogenicity, along with a low mutational burden and a unique vascular and stromal microenvironment. These conditions make it very difficult for the immune cells and molecules to penetrate into the tumors, particularly compared with the conditions in other types of cancer (77). If the microenvironment exhibits immunosuppressive qualities, checkpoint inhibition may represent a suitable goal for HCC immunotherapy, although success has been limited to date in the case of single-agent checkpoint blockade (78).

\section{Induction of ICD sensitizes blockade inhibitor therapies}

In this decade, antibodies directed against immune checkpoints have been intensely investigated in patients with cancer following the discovery by the Nobel prize winners James P. Allison and Tasuku Honjo, who demonstrated that cancer therapy can be enhanced by the inhibition of negative immune regulation (79). CTLA-4 and PD-1 are the receptors that are commonly found on the surface of activated $\mathrm{T}$ cells. The interaction of CTLA-4 and PD-1 with their ligands inhibits activated $\mathrm{T}$ cells and converts them into exhausted $\mathrm{T}$ cells, which abrogates the antitumor response. The targeting of CTLA-4 and PD-1 molecules has demonstrated durable response rates, increased survival time of responders and a manageable safety profile. Recently, checkpoint inhibition plus chemotherapy has been considered for use in the first-line setting for the treatment of CRC (11). The potential clinical responses may be associated with the induction therapy with ICD inducers and cancer immunotherapy.

It has been reported that calmodulin-binding peptide (CBP)501, a CBP that can induce ICD when combined with cisplatin treatment, can induce cell membrane exposure of CRT and the release of HMGB1. Treatment of CRC-bearing mice with CBP501 and cisplatin, and subsequently with anti PD-1 or PD-L1 antibodies, significantly enhanced the antitumor activity of immune blockade via upregulating the percentage of tumor-infiltrating $\mathrm{CD}^{+} \mathrm{T}$ cells (80). Similarly, in CRC-bearing mouse models, the combination treatment of PARP and PI3K inhibitors induced radio-sensitization and the induction of ICD. Thus, subsequent anti-CTLA-4 treatment strongly inhibited tumor growth and increased the numbers of tumor-infiltrating lymphocytes (TILs) (81). The induction treatment of not only CRC, but also HCC, has been investigated using immunogenic chemotherapy, through oxaliplatin promoting the exposure of CRT and the release of HMGB1. In $\mathrm{HCC}$, oxaliplatin combined with anti PD-1 antibodies achieved marked tumor suppression, activation of $\mathrm{CD}^{+}$ $\mathrm{T}$ cells and stimulation of DCs (82). Moreover, radiation and phototherapy are additional examples of immunogenic cancer 
therapies that sensitize the immune checkpoint blockade. CD44-targeted near-infrared photoimmunotherapy combined with anti CTLA-4 and PD-1 antibodies was shown to inhibit tumor growth and prolong the survival of CRC-bearing mice via a mechanism associated with the induction of ATP and the release of HMGB1 (83).

The ICD inducer-enhancing immune blockade has been proven in several clinical reports (Table I), but has not been well established in GI cancers. Current phase II trials have been investigating the ICD-inducing effect of 5-FU, leucovorin and oxaliplatin (FOLFOX) and FOLFOX plus irinotecan (FOLFOXIRI) to enhance the efficacy of ICIs. Patients with unresectable metastatic CRC have been treated with either FOLFOX/FOLFOXIRI or anti-PD-L1/CTLA-4 antibodies. After each treatment cycle, the safety, disease progression, death and intolerable toxicity will be continuously recorded $(84,85)$. Furthermore, the use of 5-FU and cisplatin is encouraged owing to their safety and strong enhancement of the antitumor response in advanced GC when combined with pembrolizumab (86).

The insight into the mechanism of ICD-sensitized immune blockade inhibitors is under investigation. Two possible effects have been proposed, depending on the type of ICD inducer. The first effect is the direct consequence of the chemotherapeutic agents proficiently upregulating PD-L1 expression. Those that exert this effect include 5-FU, gemcitabine, cisplatin, oxaliplatin, doxorubicin and paclitaxel (87). This is an important method for increasing the sensitivity to blockade inhibitors. Treatment with FOLFOX can activate the secretion of IFN- $\gamma$ from $\mathrm{PD}-1^{+} \mathrm{CD} 8^{+} \mathrm{T}$ cells, which is associated with the overexpression of PD-L1 on tumor cells. Hence, the combination treatment of FOLFOX with anti PD-1/PD-L1 antibodies has achieved complete cure in CRC-bearing mice, while monotherapy was unsuccessful (88). Similarly, the anthracycline drug, epirubicin, could upregulate PD-L1 expression in HCC, which causes sensitization to immune blockade therapy (89). The other effect would be due to the indirect function of ICD inducer agents via modulating the tumor microenvironment. This may be associated with the depletion of regulatory $\mathrm{T}$ cells and MDSCs that potentiates stronger antitumor responses (66). Taken together, these results from preclinical and clinical studies have indicated that the concept of priming treatment with ICD inducer agents prior to checkpoint blockade treatment could elicit a stronger antitumor response.

\section{Adoptive therapies in GI cancer}

A potential approach to cancer treatment is harnessing the properties of T cells and NK cells to attack tumor cells. NK cells and TILs are of both predictive and prognostic value in GI cancers (90). These properties can be applied through the various modalities of adoptive cell therapies, typically involving the isolation of immune cells obtained from patients diagnosed with cancer, whereupon they can be genetically modified in order to strengthen their capacity to identify and kill cancerous cells. By expanding these isolated cells ex vivo, they can then be re-introduced to the patient, in a form of treatment which can theoretically be effective for all patients with cancer who do not demonstrate adequate cancer immunity without assistance, and would therefore be incapable of responding to ICIs. Adoptive cell therapy as a cancer treatment can involve various strategies, which have either been previously examined in clinical settings, or are undergoing trials to assess their suitability against GI cancers (91). One particular approach of adoptive cell therapy makes use of the immunotherapeutic properties of cytokine-induced killer cells (CIK), which can be obtained through the treatment of peripheral blood lymphocytes using IFN- $\gamma$. This is a type of monoclonal antibody that counteracts the CD3 molecule, along with IL-2. CIK cells are predominantly expansions of $\mathrm{CD}^{+} / \mathrm{CD}^{+} / \mathrm{CD}^{2} 6^{-}$cells to become terminally differentiated CD56-positive NK cells. These are uniquely able to identify the tumor cells regardless of the presence or absence of antibodies and MHC molecules and, accordingly, have the ability to identify any tumor cells lacking MHC molecules on their surface (92). In addition to T-cell adoptive transfer, NK cell-based immunotherapy has shown promising antitumor effects in a number of studies (93-95). Adoptive transfer is being used to increase the infiltration of NK cells in the tumor site by using NK cells from different origins, such as autologous cells, allogeneic peripheral blood mononuclear cells, umbilical cord blood, human embryonic stem cells and induced pluripotent stem cells (90). However, although preclinical data indicate high efficacy of NK cell adoptive transfer in in vitro and in vivo studies, there is little information on the clinical efficiency of this method. A phase I clinical trial demonstrated that HSP70-induced activation of autologous NK cells was achieved in patients without any treatment-related negative side effects, but no significant clinical response was observed due to the high tumor burden and limited sample size (96). Moreover, adoptive macrophage transfer has recently become a hot research field $(97,98)$. Due to their innate immune function and more prominent penetrating ability, macrophages may kill tumor cells when T-cell therapy fails (99). However, sufficient clinical evidence is urgently needed to support pre-clinical data, particularly in the field of GI cancer treatment.

In order to make adoptive cell therapy more readily applicable and more effective in destroying tumor cells, relatively more recent approaches have sought to introduce antitumor antigen receptors to regular T cells, which may have promising therapeutic applications. It is possible to eliminate the requirement for MHC interaction and co-stimulatory molecules when $\mathrm{T}$ cells are engineered to include chimeric antigen receptors (CAR), in which the B-cell receptor-derived and T-cell receptor domains are combined $(100,101)$. To date, the antitumor qualities from the adoptive transfer of CAR-T cells has been evident in the case of advanced hematological malignancies, but in the case of solid tumors the results have been less promising $(102,103)$. It may be possible to explain this as a consequence of the expression of heterogeneous tumor antigens, the immunosuppressive network activity within the microenvironment of the tumor, the T-cell trafficking into solid tumors, which is less than optimal, and the absence of the necessary co-stimulatory signals to achieve CAR-T cell persistence following infusion $(100,101)$. The affinity of HER2-directed CAR-T cells for cancer cells of the GI tract is high, even for cells exhibiting low levels of HER2 expression. Moreover, CAR-T-HER2 cells may offer the potential to inhibit disease recurrence of metastasis. Specific CAR-T-HER2 cells 


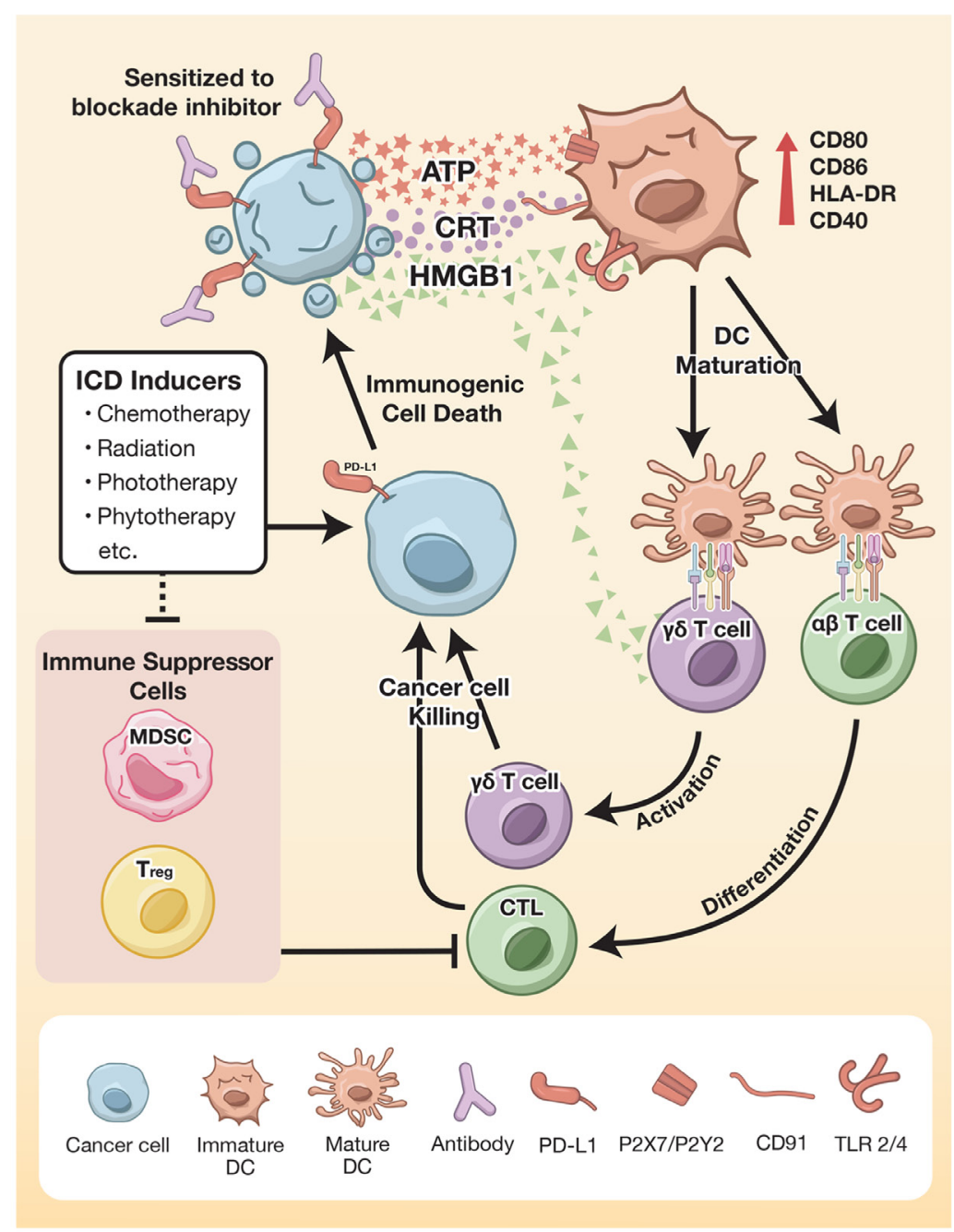

Figure 1. ICD enhances the antitumor immune response. Anticancer therapies, such as chemotherapeutic agents, radiation and phytotherapy, elicit the exposure of CRT on cell membranes and the extracellular release of ATP, HMGB1 and HSP. Interestingly, some types of ICD inducers increase PD-L1 expression, which increases the sensitivity to blockade inhibitor treatment. ICD potentiates DCs though upregulation of costimulatory signals, thereby strengthening adaptive immune system activation. Activation of $\alpha \beta$ T cells results in differentiation to cytotoxic T cells, whereas activation of $\gamma \delta \mathrm{T}$ cells is facilitated by either mature antigen-presenting cells or as a direct effect of ICD. These modulate antitumor activity by cytotoxic granules and proinflammatory cytokine production Moreover, the ICD inducer plays a role in the inhibition of immune suppressor cells. Therefore, ICD may be considered as priming therapy that may be suitably combined with cancer immunotherapy. ICD, immunogenic cell death; HMGB1, high mobility group box 1; CRT, calreticulin; MDSC, myeloid-derived suppressor cell; DC, dendritic cell; Treg, regulatory T cell; CTL, cytotoxic T lymphocyte; TLR, Toll-like receptor; PD-L1, programmed death ligand 1; HSP, heat shock protein.

have been developed, which are consistently active within the cardiovascular system, and which can accumulate within and inhibit tumors (104). In the context of PC, CAR-T-cell therapy has been the subject of a number of studies. The tumor-specific antigens of PC can be targeted by CAR-T-cell therapy. In particular, antigens that are overexpressed, such as CEA (NCT02349724), mesothelin (NCT02159716), HER2 (NCT02713984) and MUC1 (NCT02587689), are promising targets. In HCC, there have been no complete CAR-T-cell tests, but there is some evidence that the antigens CEA, MUC1 and glypican-3 could be effectively targeted $(105,106)$. For GC, only a few studies have examined CAR-T-cell therapy to date $(107,108)$, but the results are cautiously optimistic when developing CAR-T cells to target 3H11 (109), despite an inability to overcome the biological obstacles presented by solid tumors. A further study based on the overexpression of the folate 1 receptor (FOLR1) in GC compared with healthy tissue showed that FOLR1 CAR-T cells display antitumor properties by recognizing FOLR1-positive GC cells (110). In the case of hepatobiliary cancer, small-scale trials have reported positive outcomes of immunotherapy, and recent work has assessed the potential of CAR-T cells when treating cancers of the biliary tract (111). The suggested targets include EGFR, mesothelin and HER2, due to their propensity to be overexpressed in the aforementioned malignancies (112-114).

Although adoptive transfer therapy is promising and intensely under review, the major obstacle of this approach in GI cancer treatment is the heterogeneity of solid tumor, particularly in colon and GC. The heterogenicity is caused by genomic instability, which contributes to clonal evolution and immune evasion resulting in immune-resistance and tumor recurrence. Interestingly, combination treatment of cellular adoptive transfer and chemotherapy can improve clinical outcomes and may prevent recurrence in patients with advance GC that may be attributed to the synergistic effect of ICD (115). Moreover, multiclonal elimination of tumor cells could be 
improved by using multi-peptide vaccine or broad-array tumor antigen $(116,117)$. Overall, these would be the solution for immune exhaustion in clinical settings of adoptive therapies.

\section{Implications of ICD and adoptive cell transfer}

The implications of adoptive transfer of cytotoxic $\mathrm{T}$ cells or CAR-T cells with ICD has not been extensively studied in the context of GI cancer treatment. However, it has been shown that the antitumor immune response of cytotoxic T cells may lead to immunogenic tumor cell death, improving their own tumor cell-killing capacity (118). Interestingly, treatment with mitochondria-targeted small molecules, including ATP, CRT and HMGB1, can induce upregulation of ICD in both in vitro and in vivo models. This is surprising, as priming by an ICD inducer effectively suppressed tumor growth and lung metastasis by enhancing the adoptive T-cell therapy against colon cancer in a mouse model (119). Moreover, it has been demonstrated that the mitochondrial DAMPs could play a role as immunomodulators through activation of $\gamma \delta$-T cells. Mitochondrial DAMPs induced expression of TLR2 and TLR4, which may positively regulate the antitumor response $(120,121)$. TLR/type I IFN/CXCL10 has been proposed as the signaling pathway implicated in the recruitment of $\mathrm{CXCR} 3^{+} \mathrm{T}$ cells and the activation of $\gamma \delta$-T cells (122). Hence, not only the direct impact from activated antigen-presenting cells, but also T-cell-based anticancer therapy may be targeted when considering ICD (Table I). However, although the implications of T-cell therapy and ICD appear to be very promising, sufficient evidence is currently lacking.

\section{Conclusions}

ICD plays a key role in enhancing the efficacy of immunotherapy. DC-based anticancer vaccines directly activate and strengthen the co-stimulatory signal through DAMPs to further stimulate the immune response. The treatment outcomes from both the immune checkpoint blockade and adoptive transfer cell therapy may be enhanced by using ICD inducer agents. The mechanisms involving ICD-enhanced immunotherapy in GI cancer treatment are demonstrated in Fig. 1. These findings confirm the effectiveness of induction therapies combined with immunotherapy. Intervention may be implemented at only one or a few cycles at effectively low doses to avoid adverse effects and to obtain optimal ICD induction. Neoadjuvant chemotherapy can induce either cancer cell apoptosis or necrosis, which effectively promotes ICD induction, particularly HMGB1 release. In addition to the HSP family, CRT and S100 protein expression is elicited by chemotherapy and may be the primary DAMP molecules strengthening the efficacy of immunotherapy. However, the use of ICD inducers in immunotherapy for GI cancers has been limited due to a lack of research evidence, accounting for only 5-10\% of all clinical trials. Further investigation should yield more positive outcomes regarding the induction of ICD in immunotherapy for GI cancer.

\section{Acknowledgements}

Not applicable.

\section{Funding}

The present study was supported by the National Science Research and Innovation Fund (NSRF) (grant nos. R2564B011, R2564B012, R2563C029 and R2564B015) and the Thailand Science Research and Innovations (TSRI) (grant no. BRG6180010).

\section{Availability of data and materials}

Not applicable.

\section{Authors' contributions}

WS wrote the paper. $\mathrm{CN}$ designed and created the graphic figure. SP and AJ wrote and edited the paper. All authors have read and approved the final manuscript. Data authentication is not applicable.

\section{Ethics approval and consent to participate}

Not applicable.

\section{Patient consent for publication}

Not applicable.

\section{Competing interests}

The authors declare that they have no competing interests.

\section{References}

1. Rammensee HG: From basic immunology to new therapies for cancer patients. In: Cancer Immunotherapy Meets Oncology. In Honor of Christoph Huber. Britten CM, Kreiter S, Diken M and Rammensee HG (eds). Springer International Publishing, Cham, pp3-11, 2014.

2. Galluzzi L, Buqué A, Kepp O, Zitvogel L and Kroemer G: Immunogenic cell death in cancer and infectious disease. Nat Rev Immunol 17: 97-111, 2017.

3. Matzinger P: Tolerance, danger, and the extended family. Annual Rev Immunol 12: 991-1045, 1994.

4. Krysko DV, Garg AD, Kaczmarek A, Krysko O, Agostinis P and Vandenabeele P: Immunogenic cell death and DAMPs in cancer therapy. Nat Rev Cancer 12: 860-875, 2012.

5. Kroemer G, Galluzzi L, Kepp O and Zitvogel L: Immunogenic cell death in cancer therapy. Annu Rev Immunol 31: 51-72, 2013.

6. Pol J, Vacchelli E, Aranda F, Castoldi F, Eggermont A, Cremer I, Sautès-Fridman C, Fucikova J, Galon J, Spisek R, et al: Trial Watch: Immunogenic cell death inducers for anticancer chemotherapy. Oncoimmunology 4: e1008866, 2015.

7. Kepp O, Senovilla L, Vitale I, Vacchelli E, Adjemian S, Agostinis P, Apetoh L, Aranda F, Barnaba V, Bloy N, et al: Consensus guidelines for the detection of immunogenic cell death. Oncoimmunology 3: e955691, 2014.

8. Toomey PG, Vohra NA, Ghansah T, Sarnaik AA and Pilon-Thomas SA: Immunotherapy for gastrointestinal malignancies. Cancer Control 20: 32-42, 2013.

9. Rawla P and Barsouk A: Epidemiology of gastric cancer: Global trends, risk factors and prevention. Gastroenterol Rev 14: 26-38, 2019.

10. Grady WM and Carethers JM: Genomic and epigenetic instability in colorectal cancer pathogenesis. Gastroenterology 135: 1079-1099, 2008.

11. Morse MA, Hochster $\mathrm{H}$ and Benson A: Perspectives on treatment of metastatic colorectal cancer with immune checkpoint inhibitor therapy. Oncologist 25: 33-45, 2020. 
12. Bray F, Ferlay J, Soerjomataram I, Siegel RL, Torre LA and Jemal A: Global cancer statistics 2018: GLOBOCAN estimates of incidence and mortality worldwide for 36 cancers in 185 countries. CA Cancer J Clin 68: 394-424, 2018.

13. Mittal S and El-Serag HB: Epidemiology of hepatocellular carcinoma: Consider the population. J Clin Gastroenterol 47 (Suppl): S2-S6, 2013.

14. McGlynn KA and London WT: The global epidemiology of hepatocellular carcinoma: Present and future. Clin Liver Dis 15: 223-243, 2011.

15. Kamsa-Ard S, Luvira V, Suwanrungruang K, Kamsa-Ard S, Luvira V, Santong C, Srisuk T, Pugkhem A, Bhudhisawasdi V and Pairojkul C: Cholangiocarcinoma trends, incidence, and relative survival in Khon Kaen, Thailand from 1989 through 2013: A population-based cancer registry study. J Epidemiol 29: 197-204, 2019

16. Bertuccio P, Malvezzi M, Carioli G, Hashim D, Boffetta P, El-Serag HB, La Vecchia C and Negri E: Global trends in mortality from intrahepatic and extrahepatic cholangiocarcinoma. J Hepatol 71: 104-114, 2019.

17. Blechacz B: Cholangiocarcinoma: Current knowledge and new developments. Gut Liver 11: 13-26, 2017.

18. Banales JM, Marin JJG, Lamarca A, Rodrigues PM, Khan SA, Roberts LR, Cardinale V, Carpino G, Andersen JB Braconi C, et al: Cholangiocarcinoma 2020: The next horizon in mechanisms and management. Nat Rev Gastroenterol Hepatol 17: $557-588,2020$.

19. Sripa B and Pairojkul C: Cholangiocarcinoma: Lessons from Thailand. Curr Opin Gastroenterol 24: 349-356, 2008.

20. Pereira NP and Corrêa JR: Pancreatic cancer: Treatment approaches and trends. J Cancer Metastasis Treat 4: 18, 2018.

21. Matsuoka T and Yashiro M: Precision medicine for gastrointestinal cancer: Recent progress and future perspective. World J Gastrointest Oncol 12: 1-20, 2020.

22. Abdul-Latif M, Townsend K, Dearman C, Shiu KK and Khan K: Immunotherapy in gastrointestinal cancer: The current scenario and future perspectives. Cancer Treat Rev 88: 102030, 2020.

23. Tannapfel A and Reinacher-Schick A: Immunotherapy in gastrointestinal cancer: Where Do We Stand? Visc Med 35: 1-2, 2019.

24. Suntharalingam M, Winter K, Ilson DH, Dicker A, Kachnic LA, Chakravarthy AAK, Gaffney DK, Thakrar HV, Horiba MN, Deutsch M, et al: The initial report of RTOG 0436: A phase III trial evaluating the addition of cetuximab to paclitaxel, cisplatin, and radiation for patients with esophageal cancer treated without surgery. J Clin Oncol 32: LBA6-LBA6, 2014.

25. O'Connell MJ, Colangelo LH, Beart RW, Petrelli NJ, Allegra CJ, Sharif S, Pitot HC, Shields AF, Landry JC, Ryan DP, et al Capecitabine and oxaliplatin in the preoperative multimodality treatment of rectal cancer: Surgical end points from national surgical adjuvant breast and bowel project trial R-04. J Clin Oncol 32: 1927-1934, 2014

26. Mortara L, Balza E, Bruno A, Poggi A, Orecchia P and Carnemolla B: Anti-cancer therapies employing il-2 cytokine tumor targeting: Contribution of innate, adaptive and immunosuppressive cells in the anti-tumor efficacy. Front Immunol 9: $2905,2018$.

27. Hollingsworth RE and Jansen K: Turning the corner on therapeutic cancer vaccines. NPJ Vaccines 4: 7, 2019.

28. Cheever MA and Higano CS: PROVENGE (Sipuleucel-T) in prostate cancer: The first FDA-approved therapeutic cancer vaccine. Clin Cancer Res 17: 3520-3526, 2011.

29. Kudrin A: Overview of cancer vaccines: Considerations for development. Hum Vaccin Immunother 8: 1335-1353, 2012.

30. Reitsma DJ and Combest AJ: Challenges in the development of an autologous heat shock protein based anti-tumor vaccine. Hum Vaccin Immunother 8: 1152-1155, 2012.

31. Ozao-Choy J, Lee DJ and Faries MB: Melanoma vaccines: Mixed past, promising future. Surg Clin North Am 94: 1017-1030, 2014

32. Niccolai E, Taddei A, Prisco D and Amedei A: Gastric cancer and the epoch of immunotherapy approaches. World J Gastroenterol 21: 5778-5793, 2015.

33. Morse MA, Deng Y, Coleman D, Hull S, Kitrell-Fisher E, Nair S, Schlom J, Ryback ME and Lyerly HK: A Phase I study of active immunotherapy with carcinoembryonic antigen peptide (CAP-1)-pulsed, autologous human cultured dendritic cells in patients with metastatic malignancies expressing carcinoembryonic antigen. Clin Cancer Res 5: 1331-1338, 1999.

34. Li J, Valentin A, Beach RK, Alicea C, Felber BK and Pavlakis GN: DNA is an efficient booster of dendritic cell-based vaccine. Hum Vaccin Immunother 11: 1927-1935, 2015.
35. Maeda Y, Yoshimura K, Matsui H, Shindo Y, Tamesa T, Tokumitsu Y, Hashimoto N, Tokuhisa Y, Sakamoto K, Sakai K, et al: Dendritic cells transfected with heat-shock protein 70 messenger RNA for patients with hepatitis $\mathrm{C}$ virus-related hepatocellular carcinoma: A phase 1 dose escalation clinical trial. Cancer Immunol Immunother 64: 1047-1056, 2015.

36. Song W, Kong HL, Carpenter H, Torii H, Granstein R, Rafii S, Moore MA and Crystal RG: Dendritic cells genetically modified with an adenovirus vector encoding the cDNA for a mode antigen induce protective and therapeutic antitumor immunity. J Exp Med 186: 1247-1256, 1997.

37. Jiraviriyakul A, Songjang W, Kaewthet P, Tanawatkitichai P, Bayan P and Pongcharoen S: Honokiol-enhanced cytotoxic $\mathrm{T}$ lymphocyte activity against cholangiocarcinoma cells mediated by dendritic cells pulsed with damage-associated molecular patterns. World J Gastroenterol 25: 3941-3955, 2019.

38. Gottfried E, Krieg R, Eichelberg C, Andreesen R, Mackensen A and Krause SW: Characterization of cells prepared by dendritic cell-tumor cell fusion. Cancer Immun 2: 15, 2002.

39. Kavanagh B, Ko A, Venook A, Margolin K, Zeh H, Lotze M, Schillinger B, Liu W, Lu Y, Mitsky P, et al: Vaccination of metastatic colorectal cancer patients with matured dendritic cells loaded with multiple major histocompatibility complex class I peptides. J Immunother 30: 762-772, 2007.

40. Vonderheide RH, Domchek SM, Schultze JL, George DJ, Hoar KM, Chen DY, Stephans KF, Masutomi K, Loda M, $\mathrm{Xia} \mathrm{Z}$, et al: Vaccination of cancer patients against telomerase induces functional antitumor CD8+ T lymphocytes. Clin Cancer Res 10: 828-839, 2004.

41. Rosalia RA, Quakkelaar ED, Redeker A, Khan S, Camps M, Drijfhout JW, Silva AL, Jiskoot W, van Hall T, van Veelen PA, et al: Dendritic cells process synthetic long peptides better than whole protein, improving antigen presentation and T-cell activation. Eur J Immunol 43: 2554-2565, 2013.

42. Medema JP, Schuurhuis DH, Rea D, van Tongeren J, de Jong J, Bres SA, Laban S, Toes RE, Toebes M, Schumacher TN, et al: Expression of the serpin serine protease inhibitor 6 protects dendritic cells from cytotoxic $\mathrm{T}$ lymphocyte-induced apoptosis: Differential modulation by T helper type 1 and type 2 cells. J Exp Med 194: 657-667, 2001

43. Zhang QM, He SJ, Shen N, Luo B, Fan R, Fu J, Luo GR, Zhou SF, Xiao SW and Xie XX: Overexpression of MAGE-D4 in colorectal cancer is a potentially prognostic biomarker and immunotherapy target. Int J Clin Exp Pathol 7: 3918-3927, 2014

44. Kono K, Takahashi A, Sugai H, Fujii H, Choudhury AR, Kiessling $\mathrm{R}$ and Matsumoto Y: Dendritic cells pulsed with HER-2/neu-derived peptides can induce specific T-cell responses in patients with gastric cancer. Clin Cancer Res 8: 3394-3400, 2002.

45. Smith AM, Justin T, Michaeli D and Watson SA: Phase I/II study of G17-DT, an Anti-gastrin immunogen, in advanced colorectal cancer. Clin Cancer Res 6: 4719-4724, 2000.

46. Higashihara Y, Kato J, Nagahara A, Izumi K, Konishi M, Kodani T, Serizawa N, Osada T and Watanabe S: Phase I clinical trial of peptide vaccination with URLC10 and VEGFR1 epitope peptides in patients with advanced gastric cancer Int J Oncol 44 662-668, 2014

47. Mazzaferro V, Coppa J, Carrabba MG, Rivoltini L, Schiavo M, Regalia E, Mariani L, Camerini T, Marchianò A, Andreola S, et al: Vaccination with autologous tumor-derived heat-shock protein gp96 after liver resection for metastatic colorectal cancer. Clin Cancer Res 9: 3235-3245, 2003.

48. Dolcetti R, De Re V and Canzonieri V: Immunotherapy for gastric cancer: Time for a Personalized Approach? Int J Mol Sci 19: 1602, 2018

49. Le DT, Lutz E, Uram JN, Sugar EA, Onners B, Solt S, Zheng L, Diaz LA Jr, Donehower RC, Jaffee EM and Laheru DA: Evaluation of ipilimumab in combination with allogeneic pancreatic tumor cells transfected with a GM-CSF gene in previously treated pancreatic cancer. J Immunother 36: 382-389, 2013.

50. Ikeda M, Okusaka T, Ohno I, Mitsunaga S, Kondo S, Ueno H, Morizane C, Gemmoto K, Suna H, Ushida Y and Furuse J: Phase I studies of peptide vaccine cocktails derived from GPC3, WDRPUH and NEIL3 for advanced hepatocellular carcinoma. Immunotherapy 13: 371-385, 2021

51. Butterfield LH, Ribas A, Meng WS, Dissette VB, Amarnani S, Vu HT, Seja E, Todd K, Glaspy JA, McBride WH and Economou JS: T-cell responses to HLA-A*0201 immunodominant peptides derived from alpha-fetoprotein in patients with hepatocellular cancer. Clin Cancer Res 9: 5902-5908, 2003. 
52. Tsuchiya N, Yoshikawa T, Fujinami N, Saito K, Mizuno S, Sawada Y, Endo I and Nakatsura T: Immunological efficacy of glypican-3 peptide vaccine in patients with advanced hepatocellular carcinoma. Oncoimmunology 6: e1346764, 2017.

53. Zhang Q, Chen G, Peng L, Wang X, Yang Y, Liu C, Shi W, Su C, $\mathrm{Wu} \mathrm{H}$, Liu $\mathrm{X}$, et al: Increased safety with preserved antitumoral efficacy on hepatocellular carcinoma with dual-regulated oncolytic adenovirus. Clin Cancer Res 12: 6523-6531, 2006.

54. Lepisto AJ, Moser AJ, Zeh H, Lee K, Bartlett D, McKolanis JR, Geller BA, Schmotzer A, Potter DP, Whiteside T, et al: A phase I/II study of a MUC1 peptide pulsed autologous dendritic cell vaccine as adjuvant therapy in patients with resected pancreatic and biliary tumors. Cancer Ther 6: 955-964, 2008.

55. Kawamura J, Sugiura F, Sukegawa Y, Yoshioka Y, Hida JI, Hazama S and Okuno K: Multicenter, phase II clinical trial of peptide vaccination with oral chemotherapy following curative resection for stage III colorectal cancer. Oncology Lett 15: 4241-4247, 2018

56. Rahma OE, Hamilton JM, Wojtowicz M, Dakheel O, Bernstein S, Liewehr DJ, Steinberg SM and Khleif SN: The immunological and clinical effects of mutated ras peptide vaccine in combination with IL-2, GM-CSF, or both in patients with solid tumors J Transl Med 12: 55, 2014.

57. Quandt J, Schlude C, Bartoschek M, Will R, Cid-Arregui A, Schölch S, Reissfelder C, Weitz J, Schneider M, Wiemann S, et al Long-peptide vaccination with driver gene mutations in p53 and Kras induces cancer mutation-specific effector as well as regulatory T cell responses. Oncoimmunology 7: e1500671, 2018.

58. Hessmann E, Patzak MS, Klein L, Chen N, Kari V, Ramu I, Bapiro TE, Frese KK, Gopinathan A, Richards FM, et al: Fibroblast drug scavenging increases intratumoural gemcitabine accumulation in murine pancreas cancer. Gut 67: 497-507, 2018.

59. Scarpa M, Ruffolo C, Canal F, Scarpa M, Basato S, Erroi F, Fiorot A, Dall'Agnese L, Pozza A, Porzionato A, et al: Mismatch repair gene defects in sporadic colorectal cancer enhance immune surveillance. Oncotarget 6: 43472-43482, 2015.

60. Marabelle A, Le DT, Ascierto PA, Di Giacomo AM, De Jesus-Acosta A, Delord JP, Geva R, Gottfried M, Penel N, Hansen AR, et al: Efficacy of Pembrolizumab in patients with noncolorectal high microsatellite Instability/Mismatch Repair-deficient cancer: Results from the phase II KEYNOTE-158 Study. J Clin Oncol 38: 1-10, 2019.

61. Fucikova J, Kepp O, Kasikova L, Petroni G, Yamazaki T, Liu P, Zhao L, Spisek R, Kroemer G and Galluzzi L: Detection of immunogenic cell death and its relevance for cancer therapy. Cell Death Dis 11: 1013, 2020.

62. Suzuki Y, Mimura K, Yoshimoto Y, Watanabe M, Ohkubo Y, Izawa S, Murata K, Fujii H, Nakano T and Kono K: Immunogenic tumor cell death induced by chemoradiotherapy in patients with esophageal squamous cell carcinoma. Cancer Res 72: 3967-3976, 2012.

63. Ratschker T, Egenberger L, Alev M, Zschiesche L, Band J, Schreiber E, Frey B, Derer A, Alexiou C and Janko C: Mitoxantrone-loaded nanoparticles for magnetically controlled tumor therapy-induction of tumor cell death, release of danger signals and activation of immune cells. Pharmaceutics 12: 923 , 2020

64. Zhao X, Yang K, Zhao R, Ji T, Wang X, Yang X, Zhang Y, Cheng K, Liu S, Hao J, et al: Inducing enhanced immunogenic cell death with nanocarrier-based drug delivery systems for pancreatic cancer therapy. Biomaterials 102: 187-197, 2016.

65. Turrini E, Catanzaro E, Muraro MG, Governa V, Trella E, Mele V, Calcabrini C, Morroni F, Sita G, Hrelia P, et al: Hemidesmus indicus induces immunogenic death in human colorectal cancer cells. Oncotarget 9: 24443-24456, 2018

66. Wu CJ, Tsai YT, Lee IJ, Wu PY, Lu LS, Tsao WS, Huang YJ, Chang CC, Ka SM and Tao MH: Combination of radiation and interleukin 12 eradicates large orthotopic hepatocellular carcinoma through immunomodulation of tumor microenvironment Oncoimmunology 7: e1477459, 2018.

67. He H, Liu L, Liang R, Zhou H, Pan H, Zhang S and Cai L: Tumor-targeted nanoplatform for in situ oxygenation-boosted immunogenic phototherapy of colorectal cancer. Acta Biomaterialia 104: 188-197, 2020

68. Van Loenhout J, Flieswasser T, Freire Boullosa L, De Waele J, Van Audenaerde J, Marcq E, Jacobs J, Lin A, Lion E, Dewitte H, et al: Cold atmospheric plasma-treated PBS eliminates immunosuppressive pancreatic stellate cells and induces immunogenic cell death of pancreatic cancer cells. Cancers 11: $1597,2019$.
69. Pardoll DM: The blockade of immune checkpoints in cancer immunotherapy. Nat Rev Cancer 12: 252-264, 2012.

70. Tivol EA, Borriello F, Schweitzer AN, Lynch WP, Bluestone JA and Sharpe AH: Loss of CTLA-4 leads to massive lymphoproliferation and fatal multiorgan tissue destruction, revealing a critical negative regulatory role of CTLA-4. Immunity 3 : 541-547, 1995

71. Borch TH, Donia M, Andersen MH and Svane IM: Reorienting the immune system in the treatment of cancer by using anti-PD-1 and anti-PD-L1 antibodies. Drug Discov Today 20: 1127-1134, 2015.

72. Schildberg FA, Klein SR, Freeman GJ and Sharpe AH: Coinhibitory pathways in the B7-CD28 ligand-receptor family. Immunity 44: 955-972, 2016.

73. Lee B, Hutchinson R, Wong HL, Tie J, Putoczki T, Tran B, Gibbs $\mathrm{P}$ and Christie M: Emerging biomarkers for immunomodulatory cancer treatment of upper gastrointestinal, pancreatic and hepatic cancers. Semin Cancer Biol 52: 241-252, 2018.

74. Zhou G, Noordam L, Sprengers D, Doukas M, Boor PPC, van Beek AA, Erkens R, Mancham S, Grünhagen D, Menon AG, et al: Blockade of LAG3 enhances responses of tumor-infiltrating $\mathrm{T}$ cells in mismatch repair-proficient liver metastases of colorectal cancer. Oncoimmunology 7: e1448332, 2018.

75. Huyghe N, Baldin P and Van den Eynde M: Immunotherapy with immune checkpoint inhibitors in colorectal cancer: What is the future beyond deficient mismatch-repair tumours? Gastroenterol Rep (Oxf) 8: 11-24, 2020.

76. Chung KY, Gore I, Fong L, Venook A, Beck SB, Dorazio P, Criscitiello PJ, Healey DI, Huang B, Gomez-Navarro J and Saltz LB: Phase II study of the anti-cytotoxic T-Lymphocyte-associated antigen 4 monoclonal antibody, tremelimumab, in patients with refractory metastatic colorectal cancer. J Clin Oncol 28: 3485-3490, 2010.

77. Torphy RJ, Zhu Y and Schulick RD: Immunotherapy for pancreatic cancer: Barriers and breakthroughs. Ann Gastroenterol Surg 2: 274-281, 2018

78. Kudo M, Matilla A, Santoro A, Melero I, Gracian AC, Acosta-Rivera M, Choo SP, El-Khoueiry AB, Kuromatsu R, El-Rayes BF, et al: Checkmate-040: Nivolumab (NIVO) in patients (pts) with advanced hepatocellular carcinoma (aHCC) and Child-Pugh B (CPB) status. J Clin Oncol 37: 327, 2019.

79. Ledford H, Else $\mathrm{H}$ and Warren M: Cancer immunologists scoop medicine Nobel prize. Nature 562: 20-21, 2018.

80. Sakakibara K, Sato T, Kufe DW, VonHoff DD and Kawabe T: CBP501 induces immunogenic tumor cell death and CD8 T cell infiltration into tumors in combination with platinum, and increases the efficacy of immune checkpoint inhibitors against tumors in mice. Oncotarget 8: 78277-78288, 2017.

81. Landry MR, DuRoss AN, Neufeld MJ, Hahn L, Sahay G, Luxenhofer R and Sun C: Low dose novel PARP-PI3K inhibition via nanoformulation improves colorectal cancer immunoradiotherapy. Materials today Bio 8: 100082, 2020.

82. Zhu H, Shan Y, Ge K, Lu J, Kong W and Jia C: Oxaliplatin induces immunogenic cell death in hepatocellular carcinoma cells and synergizes with immune checkpoint blockade therapy. Cell Oncol (Dordr) 43: 1203-1214, 2020

83. Maruoka Y, Furusawa A, Okada R, Inagaki F, Fujimura D, Wakiyama H, Kato T, Nagaya T, Choyke PL and Kobayashi H: Near-infrared photoimmunotherapy combined with CTLA4 checkpoint blockade in syngeneic mouse cancer models. Vaccines (Basel) 8: 528, 2020.

84. Antoniotti C, Borelli B, Rossini D, Pietrantonio F, Morano F, Salvatore L, Lonardi S, Marmorino F, Tamberi S, Corallo S, et al: AtezoTRIBE: A randomised phase II study of FOLFOXIRI plus bevacizumab alone or in combination with atezolizumab as initial therapy for patients with unresectable metastatic colorectal cancer. BMC Cancer 20: 683, 2020.

85. Fumet JD, Isambert N, Hervieu A, Zanetta S, Guion JF, Hennequin A, Rederstorff E, Bertaut A and Ghiringhelli F: Phase Ib/II trial evaluating the safety, tolerability and immunological activity of durvalumab (MEDI4736) (anti-PD-L1) plus tremelimumab (anti-CTLA-4) combined with FOLFOX in patients with metastatic colorectal cancer. ESMO Open 3 : e000375, 2018

86. Bang YJ, Muro K, Fuchs CS, Golan T, Geva R, Hara H, Jalal SI, Borg C, Doi T, Wainberg ZA, et al: KEYNOTE-059 cohort 2: Safety and efficacy of pembrolizumab (pembro) plus 5-fluorouracil (5-FU) and cisplatin for first-line (1L) treatment of advanced gastric cancer. J Clin Oncol 35: 4012, 2017. 
87. Bailly C, Thuru X and Quesnel B: Combined cytotoxic chemotherapy and immunotherapy of cancer: Modern times. NAR Cancer 2: zcaa002, 2020.

88. Dosset M, Vargas TR,Lagrange A, BoidotR, VégranF, Roussey A Chalmin F, Dondaine L, Paul C, Lauret Marie-Joseph E, et al: PD-1/PD-L1 pathway: An adaptive immune resistance mechanism to immunogenic chemotherapy in colorectal cancer. Oncoimmunology 7: e1433981, 2018.

89. Chu TH, Chan HH, Hu TH, Wang EM, Ma YL, Huang SC, Wu JC, Chang YC, Weng WT, Wen ZH, et al: Celecoxib enhances the therapeutic efficacy of epirubicin for Novikoff hepatoma in rats. Cancer Med 7: 2567-2580, 2018.

90. Wang F, Lau JKC and Yu J: The role of natural killer cell in gastrointestinal cancer: Killer or helper. Oncogene 40: 717-730, 2021.

91. Amedei A, Niccolai E and D'Elios MM: T cells and adoptive immunotherapy: Recent developments and future prospects in gastrointestinal oncology. Clin Dev Immunol 2011: 320571 , 2011

92. Guo Y and Han W: Cytokine-induced killer (CIK) cells: From basic research to clinical translation. Chin J Cancer 34: 99-107, 2015

93. Sakamoto N, Ishikawa T, Kokura S, Okayama T, Oka K, Ideno M, Sakai F, Kato A, Tanabe M, Enoki T, et al: Phase I clinical trial of autologous NK cell therapy using novel expansion method in patients with advanced digestive cancer. J Transl Med 13: 277, 2015.

94. Shiozawa M, Chang CH, Huang YC, Chen YC, Chi MS, Hao HC Chang YC, Takeda S, Chi KH and Wang YS: Pharmacologically upregulated carcinoembryonic antigen-expression enhances the cytolytic activity of genetically-modified chimeric antigen receptor NK-92MI against colorectal cancer cells. BMC Immunol 19: 27, 2018

95. Liu B, Liu ZZ, Zhou ML, Lin JW, Chen XM, Li Z, Gao WB, Yu ZD and Liu T: Development of c-MET-specific chimeric antigen receptor-engineered natural killer cells with cytotoxic effects on human liver cancer HepG2 cells. Mol Med Rep 20 2823-2831, 2019

96. Krause SW, Gastpar R, Andreesen R, Gross C, Ullrich H, Thonigs G, Pfister K and Multhoff G: Treatment of colon and lung cancer patients with ex vivo heat shock protein 70-peptide-activated, autologous natural killer cells: A clinica phase i trial. Clin Cancer Res 10: 3699-3707, 2004

97. Andreesen R, Scheibenbogen C, Brugger W, Krause S, Meerpohl HG, Leser HG, Engler H and Löhr GW: Adoptive transfer of tumor cytotoxic macrophages generated in vitro from circulating blood monocytes: A new approach to cancer immunotherapy. Cancer Res 50: 7450-7456, 1990.

98. Klichinsky M, Ruella M, Shestova O, Lu XM, Best A, Zeeman M, Schmierer M, Gabrusiewicz K, Anderson NR, Petty NE, et al: Human chimeric antigen receptor macrophages for cancer immunotherapy. Nat Biotechnol 38: 947-953, 2020.

99. Liu Y and Wang R: Immunotherapy targeting tumor-associated macrophages. Front Med (Lausanne) 7: 583708, 2020.

100. Fesnak AD, June CH and Levine BL: Engineered T cells: The promise and challenges of cancer immunotherapy. Nat Rev Cancer 16: 566-581, 2016.

101. Mirzaei HR, Rodriguez A, Shepphird J, Brown CE and Badie B: Chimeric antigen receptors $\mathrm{T}$ cell therapy in solid tumor: Challenges and clinical applications. Front Immunol 8: 1850 2017.

102. Neelapu SS, Locke FL, Bartlett NL, Lekakis LJ, Miklos DB, Jacobson CA, Braunschweig I, Oluwole OO, Siddiqi T, Lin Y, et al: Axicabtagene ciloleucel CAR T-cell therapy in refractory large B-cell lymphoma. N Engl J Med 377: 2531-2544, 2017.

103. Hou B, Tang Y, Li W, Zeng Q and Chang D: Efficiency of CAR-T therapy for treatment of solid tumor in clinical trials: A meta-analysis. Disease Markers 2019: 3425291, 2019.

104. Bebnowska D, Grywalska E, Niedźwiedzka-Rystwej P, Sosnowska-Pasiarska B, Smok-Kalwat J, Pasiarski M, Góźdź S, Roliński J and Polkowski W: CAR-T cell therapy-an overview of targets in gastric cancer. J Clin Med 9: 1894, 2020.

105. Alrifai D, Sarker D and Maher J: Prospects for adoptive immunotherapy of pancreatic cancer using chimeric antigen receptor-engineered T-cells. Immunopharm Immunot 38 $50-60,2016$

106. Cheng X, Zhao G and Zhao Y: Combination immunotherapy approaches for pancreatic cancer treatment. Can J Gastroenterol Hepatol 2018: 6240467, 2018.
107. Song Y, Tong C, Wang Y, Gao Y, Dai H, Guo Y, Zhao X, Wang Y, Wang Z, Han W and Chen L: Effective and persistent antitumor activity of HER2-directed CAR-T cells against gastric cancer cells in vitro and xenotransplanted tumors in vivo. Protein Cell 9: 867-878, 2018

108. Tao K, He M, Tao F, Xu G, Ye M,Zheng Y and Li Y: Development of NKG2D-based chimeric antigen receptor-T cells for gastric cancer treatment. Cancer Chemother Pharmacol 82: 815-827, 2018.

109. Han H, Wang S, Hu Y, Li Z, Yang W, Lv Y, Wang L, Zhang L and Ji J: Monoclonal antibody $3 \mathrm{H} 11$ chimeric antigen receptors enhance $\mathrm{T}$ cell effector function and exhibit efficacy against gastric cancer. Oncol Lett 15: 6887-6894, 2018.

110. Kim M, Pyo S, Kang CH, Lee CO, Lee HK, Choi SU and Park CH: Folate receptor 1 (FOLR1) targeted chimeric antigen receptor (CAR) T cells for the treatment of gastric cancer. PLoS One 13: e0198347, 2018.

111. DeLeon TT, Zhou YM, Nagalo BM, Yokoda RT, Ahn DH, Ramanathan RK, Salomao MA, Aqel BA, Mahipal A, Bekaii-Saab TS and Borad MJ: Novel immunotherapy strategies for hepatobiliary cancers. Immunotherapy 10: 1077-1091, 2018.

112. Xu JY, Ye ZL, Jiang DQ, He JC, Ding YM, Li LF, Lv SQ, Wang Y, Jin HJ and Qian QJ: Mesothelin-targeting chimeric antigen receptor-modified $\mathrm{T}$ cells by piggyBac transposon system suppress the growth of bile duct carcinoma. Tumor Biol 39: 1010428317695949, 2017.

113. Guo Y, Feng K, Liu Y, Wu Z, Dai H, Yang Q, Wang Y, Jia H and Han W: Phase I study of chimeric antigen receptor-modified $\mathrm{T}$ cells in patients with EGFR-positive advanced biliary tract cancers. Clin Cancer Res 24: 1277-1286, 2018

114. Yan M, Schwaederle M, Arguello D, Millis SZ, Gatalica Z and Kurzrock R: HER 2 expression status in diverse cancers: Review of results from 37,992 patients. Cancer Metastasis Rev 34: $157-164,2015$

115. Cui J, Li L, Wang C, Jin H, Yao C, Wang Y, Li D, Tian H, Niu C, Wang G, et al: Combined cellular immunotherapy and chemotherapy improves clinical outcome in patients with gastric carcinoma. Cytotherapy 17: 979-988, 2015.

116. El-Sayes N, Vito A and Mossman K: Tumor heterogeneity: A great barrier in the age of cancer immunotherapy. Cancers 13: 806, 2021

117. Walter S, Weinschenk T, Stenzl A, Zdrojowy R, Pluzanska A, Szczylik C, Staehler M, Brugger W, Dietrich PY, Mendrzyk R, et al: Multipeptide immune response to cancer vaccine IMA901 after single-dose cyclophosphamide associates with longer patient survival. Nat Med 18: 1254-1261, 2012.

118. Minute L, Teijeira A, Sanchez-Paulete AR, Ochoa MC, Alvarez M, Otano I, Etxeberrria I, Bolaños E, Azpilikueta A, Garasa S, et al: Cellular cytotoxicity is a form of immunogenic cell death. J Immunother Cancer 8: e000325, 2020.

119. Jiang Q, Zhang C, Wang H, Peng T, Zhang L, Wang Y, Han W and Shi C: Mitochondria-targeting immunogenic cell death inducer improves the adoptive T-cell therapy against solid tumor. Front Oncol 9: 1196, 2019.

120. Schwacha MG, Rani M, Nicholson SE, Lewis AM, Holloway TL, Sordo S and Cap AP: Dermal $\gamma \delta$ T-cells can be activated by mitochondrial damage-associated molecular patterns. PLoS One 11: e0158993, 2016.

121. Schwacha MG, Rani M, Zhang Q, Nunez-Cantu O and Cap AP: Mitochondrial damage-associated molecular patterns activate $\gamma \delta$ T-cells. Innate immunity 20: 261-268, 2014.

122. Gebremeskel S and Johnston B: Concepts and mechanisms underlying chemotherapy induced immunogenic cell death: Impact on clinical studies and considerations for combined therapies. Oncotarget 6: 41600-41619, 2015.

123. Xie W, Forveille S, Iribarren K, Sauvat A, Senovilla L, Wang Y, Humeau J, Perez-Lanzon M, Zhou H, Martínez-Leal JF, et al: Lurbinectedin synergizes with immune checkpoint blockade to generate anticancer immunity. Oncoimmunology 8: e1656502, 2019.

124. Limagne E, Thibaudin M, Nuttin L, Spill A, Derangère V, Fumet JD, Amellal N, Peranzoni E, Cattan V and Ghiringhelli F: Trifluridine/Tipiracil plus Oxaliplatin improves PD-1 blockade in colorectal cancer by inducing immunogenic cell death and depleting macrophages. Cancer Immunol Res 7: 1958-1969, 2019.

his work is licensed under a Creative Commons

Attribution-NonCommercial-NoDerivatives 4.0 International (CC BY-NC-ND 4.0) License. 